\title{
Systematic review and meta-analysis for thrombolysis treatment in patients with acute submassive pulmonary embolism
}

This article was published in the following Dove Press journal:

Patient Preference and Adherence

28 February 2014

Number of times this article has been viewed

\section{Yaogian Cao* Haiyan Zhao* \\ Wanpeng Gao \\ Yan Wang \\ Jie Cao}

Respiratory Department, Tianjin Medical University General Hospital, Tianjin 300052, People's Republic of China

*These two authors contributed equally to this work
Correspondence: Jie Cao Respiratory Department, Tianjin Medical University General Hospital, Tianjin 300052, People's Republic of China Email tjcaojie@sina.com
Purpose: The aim of this systematic review was to evaluate the efficacy and safety of thrombolytic treatment in patients with submassive pulmonary embolism (PE).

Methods: An electronic search was carried out based on the databases from MEDLINE, Embase, Science Citation Index (SCI), and the Cochrane Library. We included prospective, randomized, and clinical trials in thrombolysis with heparin alone in adults who had evidence of right ventricular dysfunction and normotension. The main endpoints consist of mortality, recurrent $\mathrm{PE}$, and bleeding risk. The relative risk (RR) and the relevant $95 \%$ confidence intervals were determined by the dichotomous variable.

Results: Only seven studies involving 594 patients met the inclusion criteria for further review. The cumulative effect of thrombolysis, compared with intravenous heparin, demonstrated no statistically significant difference in mortality $(2.7 \%$ versus $4.3 \% ; \mathrm{RR}=0.64[0.29-1.40] ; P=0.27)$ or recurrent PE (2\% versus 5\%; RR $=0.44[0.19-1.05] ; P=0.06)$. Thrombolytic therapy did not increase major hemorrhage compared with intravenous heparin $(4.5 \%$ versus $3.3 \%$; $R R=1.16$ [0.51-2.60]; $P=0.73$ ), but it was associated with an increased minor hemorrhage ( $41 \%$ versus $9 \% ; \mathrm{RR}=3.91$ [1.46-10.48]; $P=0.007)$.

Conclusion: Compared with heparin alone, neither mortality nor recurrent $\mathrm{PE}$ is reduced by thrombolysis in patients with submassive PE, and it does not reveal an increasing risk of major bleeding. In addition, thrombolysis also produces the increased risk of minor bleeding; however, no sufficient evidence verifies the thrombolytic benefit in this review, because the number of patients enrolled in the trials is limited. Therefore, a large, double-blind clinical trial is required to prove the outcomes of this meta-analysis.

Keywords: thrombolysis treatment, submassive pulmonary embolism, pulmonary embolism, heparin, warfarin

\section{Introduction}

Acute pulmonary embolism (PE) is one of the most common, life-threatening cardiovascular events. In the past few years, the proportion of hospitalized PE patients has been gradually increasing. ${ }^{1}$ The fatality rate varies with regard to the hemodynamic status. ${ }^{2-4}$ At present, an understanding of the role of thrombolysis in the management of $\mathrm{PE}$ is not perfect. Guidelines from the American College of Chest Physicians report that for patients with acute massive PE who do not have a high bleeding risk, systemically thrombolytic therapy is suggested (grade 2C). ${ }^{5}$ Nevertheless, right ventricular dysfunction (RVD) is seen as the main pathophysiological change of acute PE, which is associated with the prognosis of patients. Studies of RV function in PE demonstrate that $50 \%$ of patients with PE discover RVD by echocardiogram; submassive PE comprises 
almost half of the nonmassive group. ${ }^{6}$ As the report indicated, the acute PE patients who are hemodynamically stable with RVD have higher mortality than those with normal right ventricular function. ${ }^{7,8}$ Regardless of the higher mortality in patients with RVD, the application of thrombolysis in submassive PE is still controversial. ${ }^{9-11}$ Hence, we conducted an advanced meta-analysis to evaluate the efficacy and safety of thrombolysis in submassive PE patients.

\section{Materials and methods}

\section{Evidence retrieval}

All randomized clinical trials for thrombolytic therapy in patients with hemodynamically stable PE were reviewed. We widely searched the following databases: MEDLINE, Embase, Science Citation Index (SCI), and the Cochrane Library 1964-2012. The keywords were "pulmonary embolism" or "thromboembolism" and "thrombolysis" or "fibrinolysis," "randomized controlled trial," "controlled clinical trial," combined with approved thrombolytic drugs - "rt-PA or alteplase or recombinant tissue plasminogen activator" and "streptokinase" and "urokinase or Abbokinase ${ }^{\circledR}$ or prourokinase." In addition, we searched again for a reference of possible included studies. Languages were not restricted to prevent the bias to publications.

\section{Study selection}

Two independent investigators executed the trial selection independently. Disagreements were settled by a consensus or by seeking an independent third viewpoint.

All enrolled studies met the following criteria: 1) the PICO question format was set up as: $\mathrm{P}=$ patient; $\mathrm{I}=$ intervention; $\mathrm{C}=$ comparison; and $\mathrm{O}=$ outcome. (Other factors included: patients [acute, submassive, pulmonary, embolism, and thromboembolism]; intervention [systemic thrombolysis and intravenous thrombolysis]; comparison [intravenous heparin, coagulation, and placebo control]; and outcome [mortality, recurrence of PE, or bleeding risk]); 2) design was defined as prospective, randomized controlled trials; and 3) PE with RVD or which was hemodynamically stable and had to be objectively confirmed by multidetector computer tomography, pulmonary angiography, or lung scanning. Those trials were excluded as follows: nonrandomized or quasirandomized, retrospective study, and comparison between thrombolytic regimens.

\section{Validity assessment and data extraction}

Two of the authors used universal criteria from the Cochrane Library Handbook 5.0.1 (Cochrane Handbook for Systematic Review of Interventions, Version 5.0.1, The Cochrane Collaboration, Oxford, UK), which includes random sequence generation, concealment of allocation, usage of blinding, incomplete outcome data, selective outcome reporting, and other potential factors.

The same author independently extracted the essential information and the endpoint from each trial. The recurrent $\mathrm{PE}$ was taken into consideration when it was mentioned in the presence of at least one of the following criteria in the original articles: 1) a new filling defect demonstrated by computed tomography or pulmonary angiography, or a new high probability perfusion defect revealed by ventilation-perfusion lung scan; 2) sudden, otherwise unexplained death; and 3) proven by autopsy. Safety outcomes included major and minor hemorrhage. The former was described as fatal bleeding, and/or symptomatic bleeding in a critical area or organ, and/or was associated with a fall in hemoglobin level of at least $2 \mathrm{~g}$ per $\mathrm{dL}$, or leading to the transfusion of two or more units of whole blood or red cells. ${ }^{12}$ Adversely, it was seen in the latter.

\section{Statistical analysis}

All statistical calculations were implemented with RevMan 5.1 software (The Nordic Cochrane Centre, Copenhagen, Denmark). We used the pooled relative risk (RR) to assess the efficacy and safety of thrombolytic therapy with $95 \%$ confidence interval (CI); $P<0.05$ was considered statistically significant. Individual trials in this meta-analysis were primarily performed by the heterogeneity test. If no significant heterogeneity was examined ( $P \geq 0.1$, by the chi-square test), the fixed-effect model and corresponding method of MantelHaenszel $(\mathrm{M}-\mathrm{H})$ were used. On the contrary, if $P<0.1$, the random-effect model was used. $I^{2}<50 \%$ was acceptable in the Cochrane Handbook for Systematic Review of Interventions, which measured the degree of heterogeneity in the research results.

\section{Results \\ Study screening, essential characteristics in enrolled trials}

Our search yielded 34 randomized controlled trials that described thrombolysis in acute PE (Figure 1). After their titles and abstracts were scanned, 27 trials were not eligible for this present meta-analysis. Also, 24 trials were excluded as they were a comparison between two regions or different protocols, or enrolled patients with massive PE among them. ${ }^{13-36}$ One study was excluded as patients were 


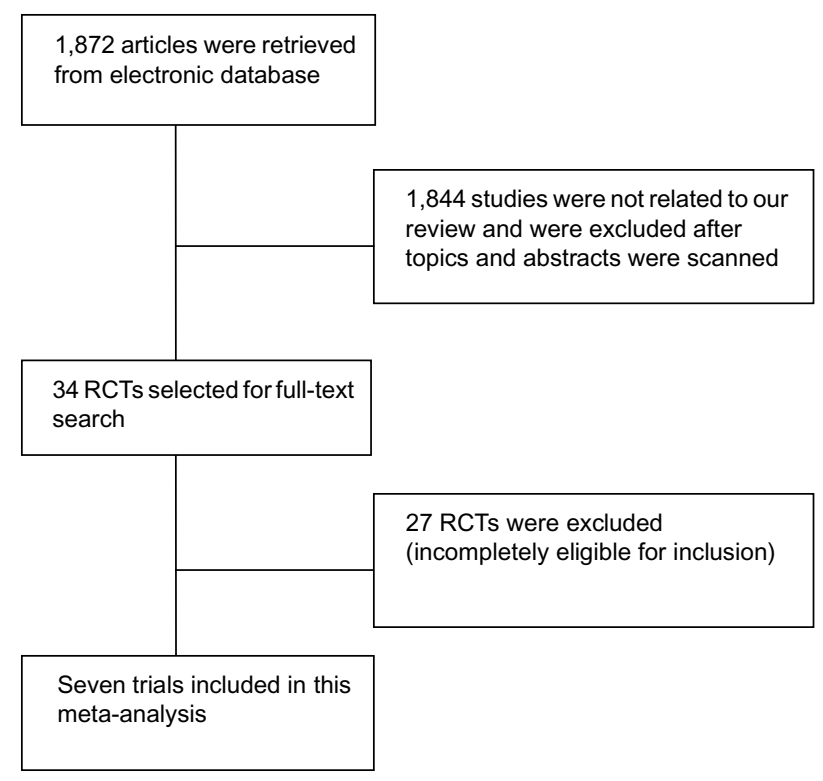

Figure I Flow chart of literature screening. Abbreviation: RCT, randomized controlled trial.

presented with acute proximal venous thrombosis. ${ }^{37}$ The other two studies were excluded because of low quality and irrelevant outcomes, respectively. ${ }^{38,39}$ Finally, seven clinical trials involving 594 patients with submassive PE were included; 291 patients were randomized to thrombolysis treatment while 303 patients were treated with heparin only.

In addition, seven trials included patients with an onset of symptoms within thrombolytic time window for acute $\mathrm{PE}$ before enrollment. All studies excluded the patients with a contraindication to thrombolysis or coagulation, as well as hemodynamic instability or shock (shock was interpreted as systolic blood pressure within $90 \mathrm{mmHg}$ ).

Alteplase was used as a thrombolysis agent in six trials while tenecteplase was used in one trial, which was administered through a peripheral vein. The heparin dose was adjusted to maintain the activated partial thromboplastin time at 2.0-2.5 times the normal. The follow-up period ranged from 7-180 days. After randomization, all enrolled patients were kept on an overlapping oral warfarin course, but only warfarin was continued after discharge and during follow-up. (Table 1).

\section{Methodological quality}

All enrolled studies were reported to be randomized, but specific random methods were mentioned in four trials. Among them, three trials reported the literature validity, while another one did not describe the allocation concealment.
The application of blind selection was relatively satisfied because double-blind selections were reported in five trials. The loss of follow-up was nonexistent in the patients in six trials (Table 2).

\section{Curative effect of thrombolysis}

Mortality and recurrence of PE were reported in all trials (Figures 2 and 3). The mean mortality in the thrombolytic group $(2.7 \%)$ was slightly lower than that in the heparin treatment alone $(4.3 \%)$, but the pooled effects were not statistically significant $(\mathrm{RR}=0.64[0.29-1.40] ; P=0.27$ ). No statistical heterogeneity was found for this endpoint (chi-square test $=5.73 ; P=0.45 ; I^{2}=0 \%$ ). The occurrence of recurrent $\mathrm{PE}$ in the thrombolytic and heparin groups was $2 \%$ and $5 \%$, respectively, which showed no statistical difference $(\mathrm{RR}=0.44$ [0.19-1.05]; $P=0.06)$. Moreover, there was no heterogeneity among trials (chi-square test $=4.73$; $\left.P=0.32 ; I^{2}=15 \%\right)$.

\section{Safety outcomes}

All trials did not demonstrate an increase in major hemorrhage after thrombolysis or heparin treatment ( $4.5 \%$ versus $3.3 \%$; $\mathrm{RR}=1.16$ [0.51-2.60]; $P=0.73$ ) (Figure 4). In addition, only four of all the trials showed significant minor hemorrhagic risk after thrombolysis treatment compared with heparin treatment (41\% versus 9\%; $R R=3.91$ [1.46-10.48]; $P=0.007$ ) (Figure 5). However, there was a certain heterogeneity for the latter (chisquare test $=6.15 ; P=0.10 ; I^{2}=51 \%$ ) (Figure 5).

\section{Funnel plot analysis}

A point on behalf of each trial on mortality was symmetrically distributed in the CI of the funnel plot (Figure 6). The symmetry of the plot did not indicate the absence of major publication bias.

\section{Discussion}

Previous meta-analyses did not provide evidence for the benefits of thrombolysis compared with heparin alone in unselected patients with acute PE. ${ }^{46,47}$ However, a mix of patients with and without shock were enrolled in randomized controlled trials of systematic reviews. No further research focused on the subset of patients with PE. Earlier studies explored the safety of thrombolytic drugs when an invasive imaging technology for PE management was universally utilized. ${ }^{48}$ The pooled estimates of presently available clinical trials indicated that either mortality or recurrence of PE was not decreased by thrombolysis when compared with heparin. Simultaneously, it was not associated with the increased risk 


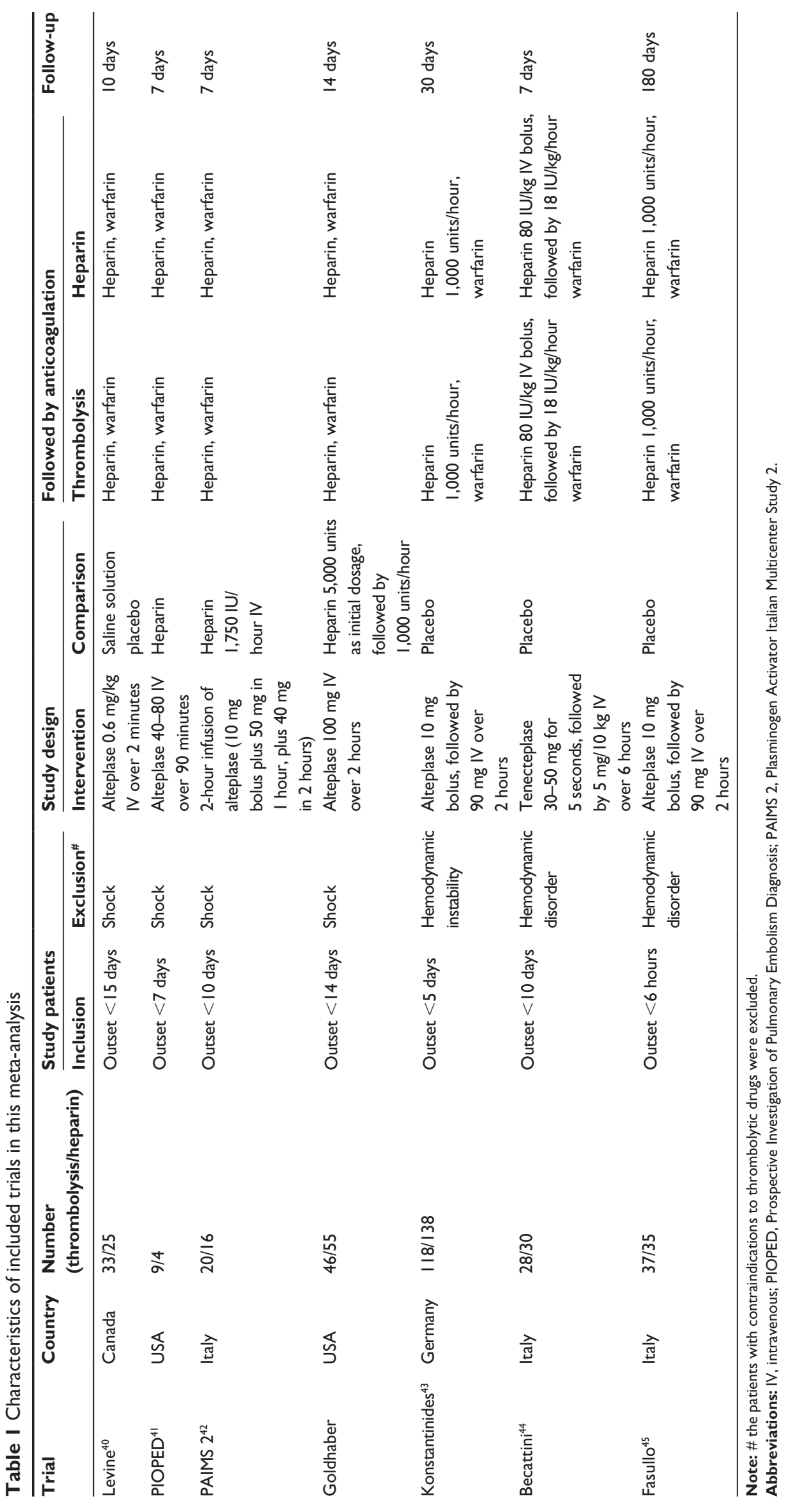


Table 2 Methodological quality of included trials

\begin{tabular}{|c|c|c|c|c|c|c|c|}
\hline Study & $\begin{array}{l}\text { Randomized } \\
\text { method }\end{array}$ & $\begin{array}{l}\text { Allocation } \\
\text { concealment }\end{array}$ & $\begin{array}{l}\text { Blinding of } \\
\text { participants }\end{array}$ & $\begin{array}{l}\text { Incomplete } \\
\text { outcome } \\
\text { data }\end{array}$ & $\begin{array}{l}\text { Selective } \\
\text { reporting }\end{array}$ & $\begin{array}{l}\text { Other } \\
\text { potential } \\
\text { factors }\end{array}$ & $\begin{array}{l}\text { Description } \\
\text { of withdrawal }\end{array}$ \\
\hline Levine $^{40}$ & Unclear & Unclear & Yes & No & Unclear & Unclear & No losses \\
\hline PIOPED ${ }^{4 I}$ & Unclear & Unclear & Yes & Yes & Unclear & Unclear & No losses \\
\hline PAIMS $2^{42}$ & Unclear & Unclear & No & No & Unclear & Unclear & No losses \\
\hline Goldhaber & Yes & Yes & No & Yes & Unclear & Unclear & Yes \\
\hline Konstantinides ${ }^{43}$ & Yes & Yes & Yes & Yes & Unclear & Unclear & No losses \\
\hline Becattini $^{44}$ & Yes & Yes & Yes & No & Unclear & Unclear & No losses \\
\hline Fasullo 45 & Yes & Unclear & Yes & No & Unclear & Unclear & No losses \\
\hline
\end{tabular}

Abbreviations: PIOPED, Prospective Investigation Of Pulmonary Embolism Diagnosis; PAIMS 2, Plasminogen Activator Italian Multicenter Study 2.

\begin{tabular}{|c|c|c|c|c|c|c|c|c|c|c|}
\hline \multirow{2}{*}{$\begin{array}{l}\text { Study or subgroup } \\
\text { Becattini } 2010^{44}\end{array}$} & \multicolumn{4}{|c|}{ bolytic therapy Heparin or placebo } & Weight & $\begin{array}{c}\text { Risk ratio } \\
M-H, \text { fixed, } 95 \%\end{array}$ & & \multicolumn{2}{|c|}{$\begin{array}{c}\text { Risk ratio } \\
\text { (M-H, fixed, } 95 \% \mathrm{Cl})\end{array}$} & \\
\hline & 0 & 28 & 1 & 30 & $9.3 \%$ & $0.36(0.02,8.40)$ & & 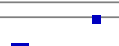 & & \\
\hline Fasullo $2011^{45}$ & 0 & 37 & 6 & 35 & $43.0 \%$ & $0.07(0.00,1.25)$ & & & & \\
\hline Goldhaber 1993 & 0 & 46 & 2 & 55 & $14.7 \%$ & $0.24(0.01,4.84)$ & & $\square$ & & \\
\hline Konstantinides $2002^{43}$ & 4 & 118 & 3 & 138 & $17.8 \%$ & $1.56(0.36,6.83)$ & & & $\square$ & \\
\hline Levine $1990^{40}$ & 1 & 33 & 0 & 25 & $3.7 \%$ & $2.29(0.10,54.05)$ & & & & \\
\hline PAIMS2 $1992^{42}$ & 2 & 20 & 1 & 15 & $7.2 \%$ & $1.60(0.16,16.10)$ & & & - & \\
\hline PIOPED $1990^{41}$ & 1 & 9 & 0 & 4 & $4.3 \%$ & $1.50(0.07,30.59)$ & & & - & \\
\hline Total $(95 \% \mathrm{Cl})$ & & 291 & & 303 & $100.0 \%$ & $0.64(0.29,1.40)$ & & & & \\
\hline Total events & 8 & & 13 & & & & & & & \\
\hline \multicolumn{7}{|c|}{ Heterogeneity: chi-square test $=5.73 ; d f=6 ;(P=0.45) ; P^{2}=0 \%$} & $\begin{aligned} & 0.01 \\
& \text { Cavor: }\end{aligned}$ & $\begin{array}{l}0.1 \\
\text { kperimental }\end{array}$ & $\begin{array}{l}10 \\
\text { Favors cont }\end{array}$ & 100 \\
\hline
\end{tabular}

Figure 2_Forest plot of the mortality compared to the thrombolysis with heparin for the patients with acute submassive PE.

Notes: The horizontal line represents $95 \%$ confidence interval of relative risk (RR), its central blue square is the position of RR, and the black diamond represents overall effect size.

Abbreviations: M-H, Mantel-Haenszel test; Cl, confidence interval; PAIMS 2, Plasminogen Activator Italian Multicenter Study 2; PIOPED, Prospective Investigation of Pulmonary Embolism Diagnosis.

\begin{tabular}{|c|c|c|c|c|c|c|c|c|c|c|}
\hline \multicolumn{6}{|c|}{ Thrombolytic therapyHeparin or placebo } & \multicolumn{2}{|l|}{ Risk ratio } & \multirow{2}{*}{\multicolumn{2}{|c|}{$\begin{array}{c}\text { Risk ratio } \\
(\mathrm{M}-\mathrm{H}, \text { fixed, } 95 \% \mathrm{Cl})\end{array}$}} & \\
\hline \multirow{2}{*}{$\begin{array}{l}\text { Study or subgroup } \\
\text { Becattini } 2010^{44}\end{array}$} & \multirow{2}{*}{$\frac{\text { Events }}{1}$} & \multirow{2}{*}{$\begin{array}{c}\text { Total } \\
28\end{array}$} & \multirow{2}{*}{$\frac{\text { Events }}{1}$} & \multicolumn{2}{|c|}{ Total Weight } & \multicolumn{2}{|c|}{ (M-H, fixed, 95\% Cl) } & & & \\
\hline & & & & 30 & $5.9 \%$ & $1.07(0.07,16.32)$ & & & {[} & \\
\hline Fasullo $2011^{45}$ & 0 & 37 & 5 & 35 & $34.4 \%$ & $0.09(0.00,1.50)$ & 4 & - & & \\
\hline Goldhaber 1993 & 0 & 46 & 5 & 55 & $30.5 \%$ & $0.11(0.01,1.91)$ & 4 & - & & \\
\hline Konstantinides $2002^{43}$ & 4 & 118 & 4 & 138 & $22.4 \%$ & $1.17(0.30,4.57)$ & & & $=$ & \\
\hline Levine $1990^{40}$ & 0 & 33 & 0 & 25 & & Not estimable & & & & \\
\hline PAIMS $21992^{42}$ & 1 & 20 & 1 & 15 & $6.8 \%$ & $0.80(0.05,11.82)$ & & & & \\
\hline PIOPED $1990^{41}$ & 0 & 9 & 0 & 4 & & Not estimable & & & & \\
\hline Total $(95 \% \mathrm{Cl})$ & & 291 & & 303 & $100.0 \%$ & $0.44(0.19,1.05)$ & & & & \\
\hline Total events & 6 & & 16 & & & & & & & \\
\hline $\begin{array}{l}\text { Heterogeneity: chi-squa } \\
\text { Test for overall effect: } Z\end{array}$ & $\begin{array}{l}t=4.73 ; d f \\
(P=0.06)\end{array}$ & $(P=0.3$ & $p^{2}=15 \%$ & & & & $\begin{array}{l}0.01 \\
\text { avors }\end{array}$ & $\begin{array}{l}0.1 \\
\text { perimental }\end{array}$ & $\begin{array}{l}10 \\
\text { Favors col }\end{array}$ & 100 \\
\hline
\end{tabular}

Figure 3 Forest plot of recurrent PE compared to the thrombolysis with heparin for the patients with acute submassive PE.

Notes: The horizontal line represents $95 \%$ confidence interval of relative risk (RR), its central blue square is the position of RR, and the black diamond represents overall effect size.

Abbreviations: M-H, Mantel-Haenszel test; Cl, confidence interval; PAIMS 2, Plasminogen Activator Italian Multicenter Study 2; PIOPED, Prospective Investigation of Pulmonary Embolism Diagnosis.

of major bleeding, but the thrombolytic therapy in PE brought significant minor hemorrhagic risk.

Thrombolytic agents have been shown to dissolve the clot rapidly and resolve the deteriorative RVD. ${ }^{49}$ However, the thrombolytic benefits in acute submassive PE have not been demonstrated in our study. In a retrospective cohort study from 392 patients, $73 \%$ of these patients were nonmassive while $27 \%$ of the patients were massive PE and were administered subcutaneously with low molecular weight heparin only, or subcutaneously with low molecular weight heparin plus thrombolytics. The mortality rate was $16.8 \%$ in patients who were massive and $3.5 \%$ for those who were nonmassive ${ }^{50}$ the latter rate was close to the mortality (4.3\%) detected in our study. Conversely, this assumption was refuted by the Registro Informatizado de la 


\begin{tabular}{|c|c|c|c|c|c|c|c|c|c|}
\hline \multicolumn{5}{|c|}{ Thrombolytic therapyHeparin or placebo } & \multirow{2}{*}{\multicolumn{2}{|c|}{$\begin{array}{c}\text { Risk ratio } \\
\text { Weight }(\mathrm{M}-\mathrm{H}, \text { fixed, } 95 \% \mathrm{Cl})\end{array}$}} & \multirow{2}{*}{\multicolumn{2}{|c|}{$\begin{array}{c}\text { Risk ratio } \\
\text { (M-H, fixed, } 95 \% \mathrm{Cl})\end{array}$}} & \\
\hline Study or subgroup & Events & Total & Events & Total & & & & & \\
\hline Becattini $2010^{44}$ & 2 & 28 & 1 & 30 & $9.3 \%$ & $2.14(0.21,22.35)$ & & - & \\
\hline Fasullo $2011^{45}$ & 2 & 37 & 1 & 35 & $9.9 \%$ & $1.89(0.18,19.95)$ & & 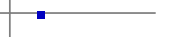 & \\
\hline Goldhaber 1993 & 3 & 46 & 1 & 55 & $8.8 \%$ & $3.59(0.39,33.33)$ & & & \\
\hline Konstantinides $2002^{43}$ & 1 & 118 & 5 & 138 & $44.3 \%$ & $0.23(0.03,1.97)$ & 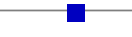 & & \\
\hline Levine $1990^{40}$ & 0 & 33 & 0 & 25 & & Not estimable & & & \\
\hline PAIMS $21992^{42}$ & 3 & 20 & 2 & 15 & $21.4 \%$ & $1.20(0.23,6.34)$ & & 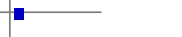 & \\
\hline PIOPED $1990^{41}$ & 1 & 9 & 0 & 4 & $6.4 \%$ & $1.50(0.07,30.59)$ & & $\cdot$ & \\
\hline Total $(95 \% \mathrm{Cl})$ & & 291 & & 303 & $100.0 \%$ & $1.16(0.51,2.60)$ & & & \\
\hline Total events & 16 & & 10 & & & & & & \\
\hline Heterogeneity: chi-squa & $s t=3.61 ; d f$ & ; $(P=0.6$ & $2=0 \%$ & & & & & & 100 \\
\hline Test for overall effect: $Z$ & $5(P=0.73)$ & & & & & Favors & sperimental & Favors control & 100 \\
\hline
\end{tabular}

Figure 4 Forest plot of major bleeding compared the thrombolysis with heparin for the patients with acute submassive PE.

Notes: The horizontal line represents $95 \%$ confidence interval of relative risk (RR), its central blue square is the position of RR, and the black diamond represents overall effect size.

Abbreviations: $\mathrm{M}-\mathrm{H}$, Mantel-Haenszel test; $\mathrm{Cl}$, confidence interval; PAIMS 2, Plasminogen Activator Italian Multicenter Study 2; PIOPED, Prospective Investigation of Pulmonary Embolism Diagnosis.

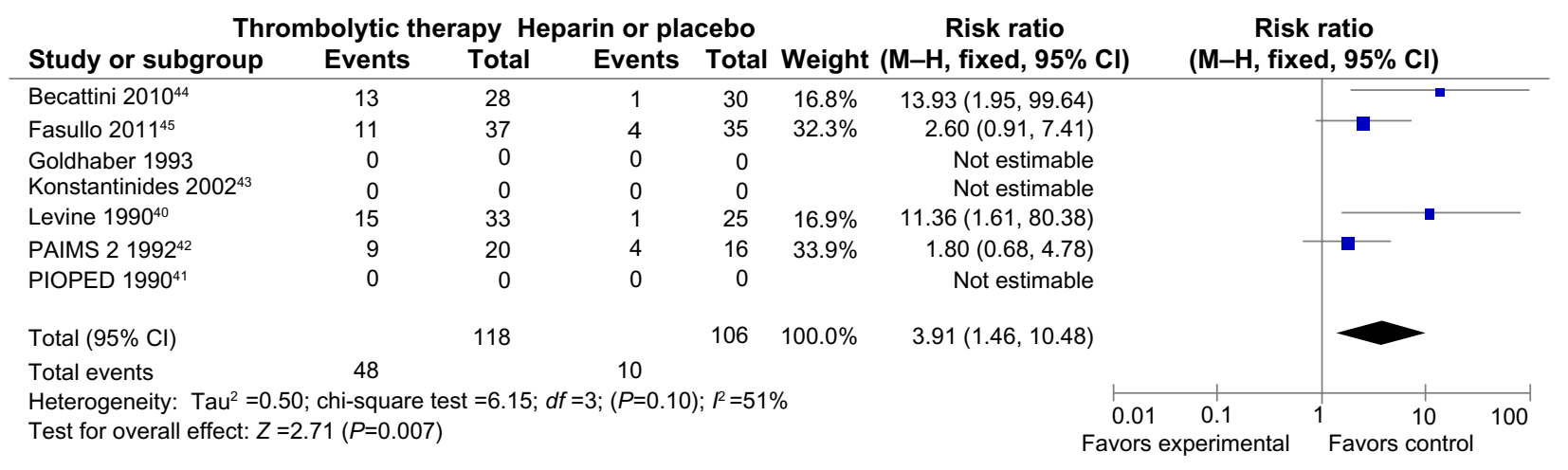

Figure 5 Forest map of minor bleeding compared the thrombolysis with heparin for the patients of acute submassive PE.

Notes: The horizontal line represents $95 \%$ confidence interval of relative risk (RR), its central blue square is the position of RR, and the black diamond represents overall effect size.

Abbreviations: $\mathrm{M}-\mathrm{H}$, Mantel-Haenszel test; Cl, confidence interval; PAIMS 2, Plasminogen Activator Italian Multicenter Study 2; PIOPED, Prospective Investigation of Pulmonary Embolism Diagnosis.

Enfermedad TromboEmbólica (RIETE Registry) that included 15,944 patients with symptomatic acute PE. In the normotensive subgroup, thrombolysis brought a more significant risk of death than no thrombolysis during the 3-month follow-up. ${ }^{51}$

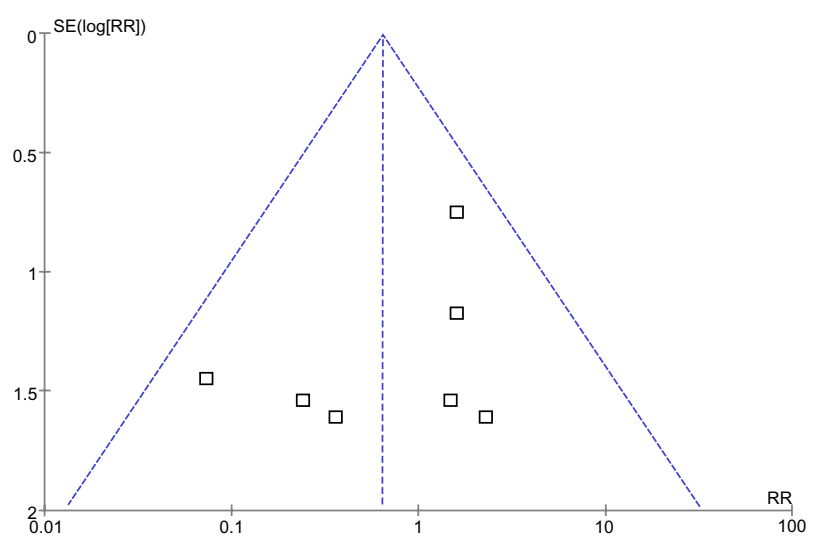

Figure 6 Funnel plot of overall effect for mortality versus study precision. Abbreviations: SE, standard error; RR, relative risk.
In addition, the recurrent $\mathrm{PE}$ was the leading cause of death in patients with submassive PE; therefore, the mortality was close to the PE recurrence rate from this meta-analysis. This outcome was in accordance with the result of the retrospective cohort study reported by Hamel et al..$^{52}$

The $13 \%$ cumulative rate of major hemorrhage was reported in the pooled data, ${ }^{53}$ including clinical trials that compared thrombolysis with heparin alone or different thrombolytic regimens with each other. This incidence was apparently higher than the rate in our review (4.5\%). Nevertheless, major bleeding has been seldom seen in the largest trials as a result of an advanced noninvasive imaging technique in recent years. ${ }^{43}$ The safety of thrombolytic therapy in our study was not influenced by an overdose of warfarin in the follow-up period.

There are some limitations in our meta-analysis. The number of patients with hemodynamically stable or RVD confirmed by echocardiography was flat, so that the relevant statistical power was confined. The endpoint of our systematic 
review remains debatable, because the small sample capacity precludes us making reliable conclusions. The Pulmonary EmbolIsm THrOmbolysis trial (PEITHO) has been planned as a prospective, multicenter, randomized, double-blind, placebo-controlled trial in patients with submassive PE. This trial is expected to enroll approximately 1,000 patients who have evidence of RVD and normotension, with a view to evaluate the superiority of tenecteplase. ${ }^{54}$ Data collection for the primary outcome measure of this trial has been completed. The primary efficacy outcome is composed of death from any cause or hemodynamic collapse, which is different from a previous large trial included in the present meta-analysis. Another outcome is to assess ischemic or hemorrhagic stroke with regards to the safety outcomes; moderate and severe bleeding are included and specified. The estimated study completion date is in July 2014. However, the conclusion of the PEITHO trial is to only account for the clinical benefit of a new agent while our study covers all approved thrombolytic drugs.

In conclusion, this systematic review did not demonstrate the clinical benefits of thrombolytic treatment in patients with an acute submassive pulmonary embolism. Thrombolysis could be beneficial to the patients with severe RVD or emerging hemodynamically instability (selected high risk patients).

With the application of a noninvasive diagnostic device in the modern management of PE, major bleeding is significantly less frequent in the largest trials compared with earlier ones. ${ }^{6,43}$ A large, double-blind, randomized controlled trial is required to prove the outcomes of this meta-analysis because the number of patients enrolled in the trials is limited.

\section{Disclosure}

The authors report no conflicts of interest in this work.

\section{References}

1. Stein PD, Matta F. Epidemiology and incidence: the scope of the problem and risk factors for development of venous thromboembolism. Crit Care Clin. 2011;27(4):907-932.

2. Stein PD, Matta F, Keyes DC, Willyerd GL. Impact of vena cava filters on in-hospital case fatality rate from pulmonary embolism. Am J Med. 2012;125(5):478-484.

3. Stein PD, Matta F. Thrombolytic therapy in unstable patients with acute pulmonary embolism: saves lives but underused. Am J Med. 2012;125(5):465-470.

4. Stein PD, Matta F. Case fatality rate with pulmonary embolectomy for acute pulmonary embolism. Am J Med. 2012;125(5):471-477.

5. Kearon C, Akl EA, Comerota AJ, et al; American College of Chest Physicians. Antithrombotic therapy for VTE disease: Antithrombotic Therapy and Prevention of Thrombosis, 9th ed: American College of Chest Physicians Evidence-Based Clinical Practice Guidelines. Chest. 2012;141(Supp1 2):e419S-e494S.
6. Goldhaber SZ, Haire WD, Feldstein ML, et al. Alteplase versus heparin in acute pulmonary embolism: randomised trial assessing right-ventricular function and pulmonary perfusion. Lancet. 1993;341(8844): 507-511.

7. Ribeiro A, Lindmarker P, Juhlin-Dannfelt A, Johnsson H, Jorfeldt L. Echocardiography Doppler in pulmonary embolism: right ventricular dysfunction as a predictor of mortality rate. Am Heart J. 1997;134(3): $479-487$.

8. Grifoni S, Olivotto I, Cecchini P, et al. Short-term clinical outcome of patients with acute pulmonary embolism, normal blood pressure, and echocardiographic right ventricular dysfunction. Circulation. 2000;101(24):2817-2822.

9. Kearon C, Kahn SR, Agnelli G, Goldhaber S, Raskob GE, Comerota AJ. American College of Chest Physicians. Antithrombotic therapy for venous thromboembolic disease: American College of Chest Physicians Evidence-Based Clinical Practice Guidelines (8th Edition). Chest. 2008;133(Suppl 6):454S-545S.

10. British Thoracic Society Standards of Care Committee Pulmonary Embolism Guideline Development Group. British Thoracic Society guidelines for the management of suspected acute pulmonary embolism. Thorax. 2003;58(6):470-483.

11. Piazza G, Goldhaber SZ. Management of submassive pulmonary embolism. Circulation. 2010;122(11):1124-1129.

12. Schulman S, Kearon C; Subcommittee on Control of Anticoagulation of the Scientific and Standardization Committee of the International Society on Thrombosis and Haemostasis. Definition of major bleeding in clinical investigations of antihemostatic medicinal products in nonsurgical patients. J Thromb Haemost. 2005;3(4):692-694.

13. Miller GA, Sutton GC, Kerr IH, Gibson RV, Honey M. Comparison of streptokinase and heparin in treatment of isolated acute massive pulmonary embolism. Br Med J. 1971;2(5763):681-684.

14. Bell WR, Simon TL, Stengle JM, Sherry S. The urokinase-streptokinase pulmonary embolism trial (phase II) results. Circulation. 1974;50(6): 1070-1071.

15. Sasahra AA, Bell WR, Simon TL, Stengle JM, Sherry S. The phase II urokinase-streptokinase pulmonary embolism trial: a national cooperative study. Thromb Diath Haemorrh. 1975;33(3):464-476.

16. Bell WR. Streptokinase and urokinase in the treatment of pulmonary thromboemboli; from a national cooperative study. Thromb Haemost. 1976;35(1):57-69.

17. Charbonnier B. [Multicenter study of 2 urokinase protocols in severe pulmonary embolism. Research Group on Urokinase and Pulmonary Embolism]. Arch Mal Coeur Vaiss. 1984;77(7):773-781. French [with English abstract].

18. Giuntini C, Marini C, Di Ricco G, Palla R, Giacomelli V, Rindi M. A controlled clinical trial on the effect of heparin infusion and two regimens of urokinase in acute pulmonary embolism. G Ital Cardiol. 1984;14 Suppl 1:26-29.

19. François G, Charbonnier B, Raynaud P, Garnier LF, Griguer P, Brochier M. [Treatment of acute pulmonary embolism with urokinase compared with the combination plasminogen-urokinase. Apropos of 67 cases]. Archives des Maladies du Coeur et des Vaisseaux. 1986;79(4):435-442. French [with English abstract].

20. Goldhaber SZ, Kessler CM, Heit J, et al. Randomised controlled trial of recombinant tissue plasminogen activator versus urokinase in the treatment of acute pulmonary embolism. Lancet. 1988;2(8606): 293-298.

21. Sasahara AA, Henkin J, Janicki RS, et al. Urokinase versus tissue plasminogen activator in pulmonary embolism. Lancet. 1988;2(8612): 691-692.

22. Verstraete M, Miller GA, Bounameaux H, et al. Intravenous and intrapulmonary recombinant tissue-type plasminogen activator in the treatment of acute massive pulmonary embolism. Circulation. 1988;77(2):353-360.

23. Goldhaber SZ. TPA versus urokinase in acute pulmonary embolism: results of a randomized controlled trial. Vasa Suppl. 1989;27:292-294.

24. Goldhaber SZ, Kessler CM, Heit JA, et al. Recombinant tissue-type plasminogen activator versus a novel dosing regimen of urokinase in acute pulmonary embolism: a randomized controlled multicenter trial. J Am Coll Cardiol. 1992;20(1):24-30. 
25. Meyer G, Sors H, Charbonnier B, et al. Effects of intravenous urokinase versus alteplase on total pulmonary resistance in acute massive pulmonary embolism: a European multicenter double-blind trial. The European Cooperative Study Group for Pulmonary Embolism. J Am Coll Cardiol. 1992;19(2):239-245.

26. Sors H, Pacouret G, Azarian R, Meyer G, Charbonnier B, Simonneau G. Hemodynamic effects of bolus vs 2-h infusion of alteplase in acute massive pulmonary embolism. A randomized controlled multicenter trial. Chest. 1994;106(3):712-717.

27. Goldhaber SZ, Agnelli G, Levine MN. Reduced dose bolus alteplase vs conventional alteplase infusion for pulmonary embolism thrombolysis. An international multicenter randomized trial. The Bolus Alteplase Pulmonary Embolism Group. Chest. 1994;106(3):718-724.

28. Agnelli G, Iorio A, Parise P, Goldhaber SZ, Levine MN. Fibrinogenolysis and thrombin generation after reduced dose bolus or conventional rt-PA for pulmonary embolism. The Coagulation Project Investigators of the Bolus Alteplase Pulmonary Embolism Group. Blood Coagul Fibrinolysis. 1997;8(4):216-222.

29. Meneveau N, Schiele F, Vuillemenot A, et al. Streptokinase vs alteplase in massive pulmonary embolism. A randomized trial assessing right heart haemodynamics and pulmonary vascular obstruction. Eur Heart J. 1997;18(7):1141-1148.

30. Meneveau N, Schiele F, Metz D, et al. Comparative efficacy of a two-hour regimen of streptokinase versus alteplase in acute massive pulmonary embolism: immediate clinical and hemodynamic outcome and one-year follow-up. J Am Coll Cardiol. 1998;31(5): 1057-1063

31. Tebbe U, Graf A, Kamke W, et al. Hemodynamic effects of double bolus reteplase versus alteplase infusion in massive pulmonary embolism. Am Heart J. 1999;138(1):39-44.

32. Wang C, Zhai Z, Yang Y, et al; China Venous Thromboembolism Study Group. Efficacy and safety of 2-hour urokinase regime in acute pulmonary embolism: a randomized controlled trial. Respir Res. 2009;10(1):128.

33. Wang C, Zhai Z, Yang Y, et al; China Venous Thromboembolism (VTE) Study Group. Efficacy and safety of low dose recombinant tissue-type plasminogen activator for the treatment of acute pulmonary thromboembolism: a randomized, multicenter, controlled trial. Chest. 2010;137(2):254-262.

34. Wu YQ, Tao LB, Lü C, Hu YH. [An economic evaluation of low dose recombinant human tissue-type plasminogen activator for the treatment of acute pulmonary thromboembolism]. Zhonghua Yi Xue Za Zhi. 2010;90(2):103-106. Chinese [with English abstract].

35. Abdelsamad AA, El-Morsi AS, Mansour AE. Efficacy and safety of high dose versus low dose streptokinase for treatment of submassive pulmonary embolism. The Egyptian Heart Journal. 2011;63(2):67-72.

36. Yang Y, Wang Y, Ma Z, et al. Efficacy and safety of two-hour regimen of recombinant streptokinase versus urokinase in massive and submassive pulmonary embolism: A randomized controlled trial. Respirology. 2011;16:309.

37. Elliot MS, Immelman EJ, Jeffery P, et al. A comparative randomized trial of heparin versus streptokinase in the treatment of acute proximal venous thrombosis: an interim report of a prospective trial. Br J Surg. 1979;66(12):838-843.

38. Dotter CT, Seaman AJ, Rösch J, Porter JM. Streptokinase and heparin in the treatment of pulmonary embolism: a randomized comparison. Vascular and Endovascular Surgery. 1979;13(1):42-52.

Patient Preference and Adherence

\section{Publish your work in this journal}

Patient Preference and Adherence is an international, peer-reviewed, open access journal focusing on the growing importance of patient preference and adherence throughout the therapeutic continuum. Patient satisfaction, acceptability, quality of life, compliance, persistence and their role in developing new therapeutic modalities and compounds to
39. Sharma GVRK, Burleson VA, Sasahara AA. Effect of thrombolytic therapy on pulmonary-capillary blood volume in patients with pulmonary embolism. $N$ Engl J Med. 1980;303(15):842-845.

40. Levine M, Hirsh J, Weitz J, et al. A randomized trial of a single bolus dosage regimen of recombinant tissue plasminogen activator in patients with acute pulmonary embolism. Chest. 1990;98(6):1473-1479.

41. Tissue plasminogen activator for the treatment of acute pulmonary embolism. A collaborative study by the PIOPED Investigators. Chest. 1990;97(3):528-533.

42. Dalla-Volta S, Palla A, Santolicandro A, et al. PAIMS 2: alteplase combined with heparin versus heparin in the treatment of acute pulmonary embolism. Plasminogen activator Italian multicenter study 2. J Am Coll Cardiol. 1992;20(3):520-526.

43. Konstantinides S, Geibel A, Heusel G, Heinrich F, Kasper W. Management Strategies and Prognosis of Pulmonary Embolism-3 Trial Investigators. Heparin plus alteplase compared with heparin alone in patients with submassive pulmonary embolism. $N$ Engl J Med. 2002;347(15):1143-1150

44. Becattini C, Agnelli G, Salvi A, et al; TIPES Study Group. Bolus tenecteplase for right ventricle dysfunction in hemodynamically stable patients with pulmonary embolism. Thromb Res. 2010;125(3): e82-e86.

45. Fasullo S, Scalzo S, Maringhini G, et al. Six-month echocardiographic study in patients with submassive pulmonary embolism and right ventricle dysfunction: comparison of thrombolysis with heparin. Am J Med Sci. 2011;341(1):33-39.

46. Thabut G, Thabut D, Myers RP, et al. Thrombolytic therapy of pulmonary embolism: a meta-analysis. J Am Coll Cardiol. 2002;40(9): 1660-1667.

47. Wan S, Quinlan DJ, Agnelli G, Eikelboom JW. Thrombolysis compared with heparin for the initial treatment of pulmonary embolism: a metaanalysis of the randomized controlled trials. Circulation. 2004;110(6): 744-749.

48. Konstantinides S. Clinical practice. Acute pulmonary embolism. N Engl J Med. 2008;359(26):2804-2813.

49. Goldhaber SZ, Visani L, De Rosa M. Acute pulmonary embolism: clinical outcomes in the International Cooperative Pulmonary Embolism Registry (ICOPER). Lancet. 1999;353(9162):1386-1389.

50. Ucar EY, Araz O, Akgun M, et al. Low-molecular-weight heparin use with thrombolysis: is it effective and safe? Ten years' clinical experience. Respiration. 2013;86(4):318-323.

51. Riera-Mestre A, Jiménez D, Muriel A, et al; RIETE investigators. Thrombolytic therapy and outcome of patients with an acute symptomatic pulmonary embolism. J Thromb Haemost. 2012;10(5):751-759.

52. Hamel E, Pacouret G, Vincentelli D, et al. Thrombolysis or heparin therapy in massive pulmonary embolism with right ventricular dilatation: results from a 128-patient monocenter registry. Chest. 2001;120(1): 120-125.

53. Konstantinides S, Marder VJ. Thrombolysis in venous thromboembolic disease. In: Colman RW, Marder VJ, Clowes AW, George JN, Goldhaber SZ, editors. Hemostasis and Thrombosis: Basic Principles and Clinical Practice. 5th ed. Philadelphia, PA: Lippincott Williams \& Wilkins; 2006:1317-1329.

54. Assistance Publique, Hôpitaux de Paris. PEITHO pulmonary embolism thrombolysis study. Available from http:/clinicaltrials.gov/ct2/ show/NCT00639743?term=PEITHO+pulmonary+embogov/ct2/ show/NCT00639743?term=PEITHO+pulmonary+embolism+thro mbolysis+study\&rank=1. NLM identifier: NCT00639743. Accessed December 21, 2011.

optimize clinical outcomes for existing disease states are major areas of interest. This journal has been accepted for indexing on PubMed Central. The manuscript management system is completely online and includes a very quick and fair peer-review system. Visit http://www.dovepress.com/ testimonials.php to read real quotes from published authors. 